\title{
Erbium bis(pentafluorophenyl)phosphinate: a new hybrid material with unusually long-lived infrared luminescence
}

\author{
Y. Zheng $\cdot$ J. Pearson $\cdot$ R. H. C. Tan $\cdot$ \\ W. P. Gillin · P. B. Wyatt
}

Published online: 28 May 2009

(C) Springer Science+Business Media, LLC 2009

Erratum to: J Mater Sci: Mater Electron

(2009) 20:S430-S434

DOI 10.1007/s10854-008-9662-9

There is an error in the calculation of the average luminescence lifetime, $\langle\tau\rangle$, using the experimentally determined values $\tau=237 \mu \mathrm{s}$ and $\beta=0.7$ in the equation for $\langle\tau\rangle$ presented on page S432. The correct value is $\langle\tau\rangle=$ $0.30 \mathrm{~ms}$. We are grateful to Professor J.-C. Bünzli for informing us of our error.

Figure 3 inadvertently showed the photoluminescence emission spectrum of $\left[\left(\mathrm{C}_{6} \mathrm{~F}_{5}\right)_{2} \mathrm{PO}_{2}\right]_{3} \mathrm{Er}(5)$. The correct version of Fig. 3 , showing the spectrum of $\left[\left(\mathrm{C}_{6} \mathrm{H}_{5}\right)_{2}\right.$ $\left.\mathrm{PO}_{2}\right]_{3} \operatorname{Er}(\mathbf{6})$, is given below.

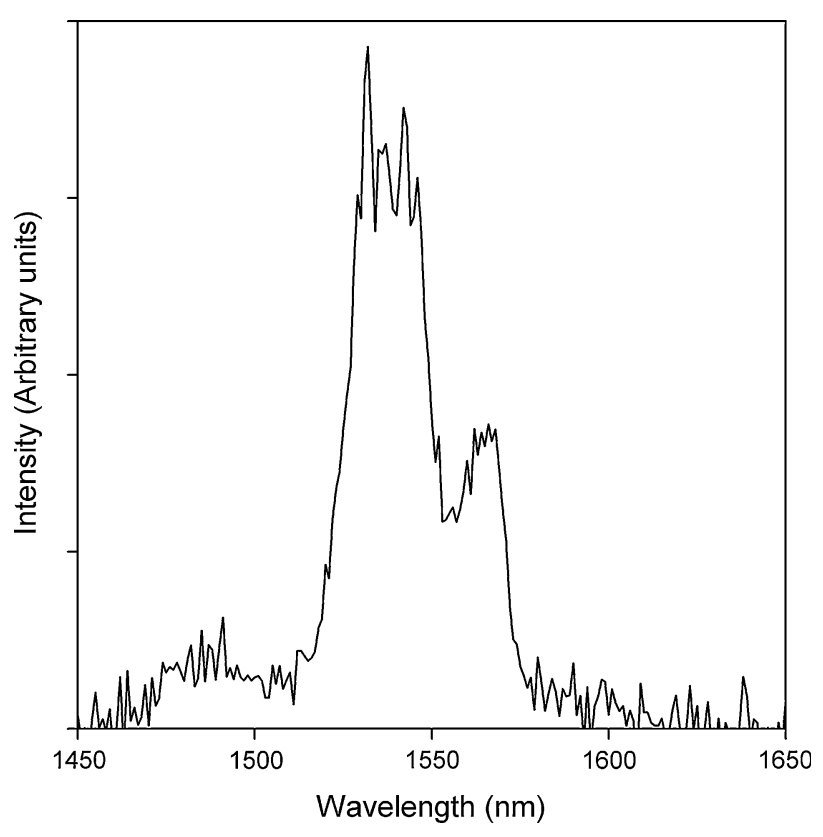

Fig. 3 Photoluminescence emission spectrum for $\left[\left(\mathrm{C}_{6} \mathrm{H}_{5}\right)_{2} \mathrm{PO}_{2}\right]_{3} \mathrm{Er}(\mathbf{6})$

The online version of the original article can be found under doi:10.1007/s10854-008-9662-9.

Y. Zheng · J. Pearson · R. H. C. Tan · W. P. Gillin ·

P. B. Wyatt $(\bowtie)$

Centre for Materials Research, Faculty of Natural Sciences,

Queen Mary, University of London, Mile End Road,

London E1 4NS, UK

e-mail: p.b.wyatt@qmul.ac.uk 